\title{
Research Article \\ Optimal method for production of mycelia biomass of Ganoderma lucidum in sugarcane molasses
}

\section{SAEIDEH AHMADIFAR, SYED MOHSEN HOSSEINI, EBRAHIM MOHAMMADI GOLTAPEH ${ }^{\bowtie}$, AKBAR JAHEDI}

Faculty of Agriculture, Tarbiat Modares University, Tehran, Iran

Received: 09.11.2019

Accepted: 01.02.2020

Ahmadifar S , Hosseini SM, MohammadiGoltapeh E, Jahedi A (2020) Optimal method for production of mycelia biomass of Ganoderma lucidum in sugarcane molasses.

Plant Pathology Science 9(1):1-14. DOI: 10.2982/PPS.9.1.1.

\begin{abstract}
Introduction: Ganoderma lucidum, medicinal mushroom, is one of the most effective traditional medicine in East Asia. The mycelium, the spore and the basidiocarp contain about 400 different bioactive compounds with polysaccharides, peptidoglycans and triterpenes as active ingredient groups of medical value. Underwater cultivation is one of the most reliable technologies to produce the industrial biomass of this mushroom, which contains anti-tumor and anti-cancer polysaccharides. Regarding the growth of fungal mycelium, it is related to various environmental factors such as $\mathrm{pH}$, temperature and available nutrients. The aim of this study was to determine the influence of $\mathrm{pH}$, temperature and different concentrations of the carbon and nitrogen sources on the growth rate of fungal biomass in sugar cane molasses. Materials and Methods: The first part of the study dealt with the morpHological and molecular identification of an Iranian isolate from G. lucidum. Then the effects of carbon sources of arabinose, maltose, cellulose and xylose at concentrations of $0.1,0.2$ and $0.3 \%$, and nitrogen sources of yeast extract, $\mathrm{MgSo}_{4} .7 \mathrm{H} 2 \mathrm{O}$, peptone and $\mathrm{K}_{2} \mathrm{Hpo}_{4}$ at concentrations of $0.2,0.3$ and $0.4 \%, \mathrm{pH} 4,4.5,5$ and 5.5, and a temperature of $25^{\circ} \mathrm{C}, 28^{\circ} \mathrm{C}, 32^{\circ} \mathrm{C}$ and the number of 2,3 , and 4 inoculum particles of $5 \mathrm{~mm}^{2}$ for the production of mycelium biomass of G. lucidum, in sugarcane molasses was studied, in completely randomized design experiments with four replicates for each treatment in vitro. Results: A comparison of the mean dry weight mycelium of G. lucidum produced with different treatments showed the significant differences between the treatments with a probability of $5 \%$. The highest yield of G. lucidum was obtained in peptone with concentration of $0.3 \%$, maltose with concentration of $0.2 \%, \mathrm{pH}=5,3$ inoculum particles with $5 \mathrm{~mm}^{2}$ diameter, at $28^{\circ} \mathrm{C}$. Conclusion: Sugar cane molasses can be used as a cheap and inexpensive medium for the biomass production of G. lucidum. For the first time this study showed that by adding peptone with concentration of $0.3 \%$, maltose with concentration of $0.2 \%$, to sugarcane molasses, with 3 particles of inoculum with $5 \mathrm{~mm}^{2}$ diameter, in $\mathrm{pH}=5$, and $28^{\circ} \mathrm{C}$, the highest biomass of this medicinal mushroom could be produced.
\end{abstract}

Keywords: Peptone, Immersed cultivation, Maltose, Sugarcane molasses, Ganoderma

$\triangle$ emgoltapeh@gmail.com 
مقاله يخووهشى

روش بهينه توليد زيست توده ميسليومى Ganoderma lucidum در ملاس نيشكر

سعيده احمدىفر، سيد محسن حسينى، ابراهيم محمدى گَلتيه هـ، اكبر جاهدى

دانشكده كشاورزى، دانشخاه تربيت مدرس، تهران

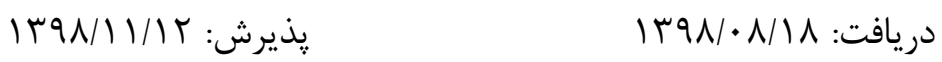

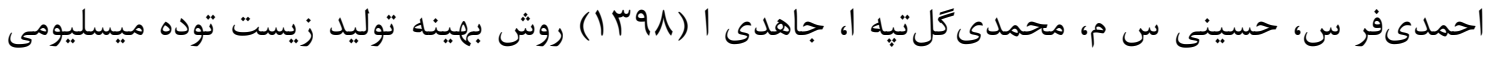
Ganoderma lucidum

DOI:10.2982/PPS.9.1.1.

جكيده

مقدمه: قارج دارويى Ganoderma lucidum بهعنوان يكى از موثرترين محصولهاى طبسنتى در شرق آسيا شناخته شده است. بدنه بازيديوكارب، ميسليوم و اسيور اين قارج حاوى حدود . F تركيب مختلف زيست فعال بههمراه يلى مىباشند. براى توليد مقياس بزركى از زيستتوده اين قارج حاوى يلى غوطهور آن يكى از موثقترين فنآورىها است. با توجه به اينكه رشد ميسليوم قارج با عوامل محيطى مختلف

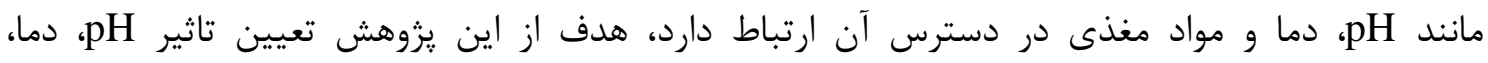
غلظتهاى مختلف منبع كربن و نيتروزن بر رشد زيست توده قارت در محيط ملاس نيشكر بود. مواد و روشها: بخش اول يزوهش به شناسايى ريختى و مولكولى جدايه ايرانى G. lucidum اختصاص داده

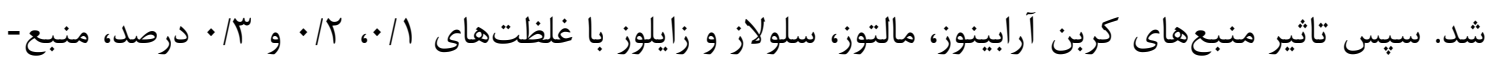
هاى نيتروزن عصاره مخمر، MgSo $7 \mathrm{H}_{2} \mathrm{O}$

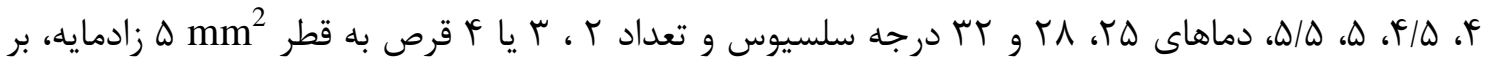
توليد زيست توده ميسليومى G. lucidum در ملاس نيشكر، در آزمايشهاى در قالب طرح آمارى كاملا تصادفى با :جهار تكرار براى هر تيمار در شرايط آزمايشگاهى مطالعه شدند. يافتهها: مقايسه ميانگين وزن خشك ميسليوم توليدى در تيمارهاى مختلف اين آزمايش نشان داد كه بين تيمارهاى مختلف در سطح احتمال هدرصد اختلاف معنىىارى وجود دارد. بيشترين توده ميسليومى قارج با منبع نيتروزن پيرتون با

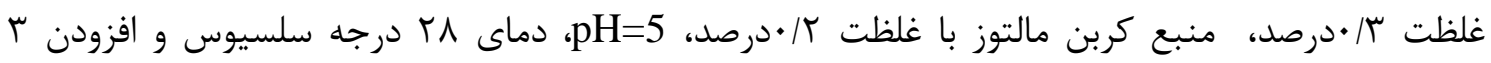
قرص به قطر 5mm² زادمايه قارج در محيط مايع ملاس نيشكر بدست آمد. نتيجه كيرى: ملاس نيشكر مىتواند بهعنوان يك محيط ارزان و مقرونبهصرفه براى توليد زيستتوده G. lucodum مورد استفاده قرار

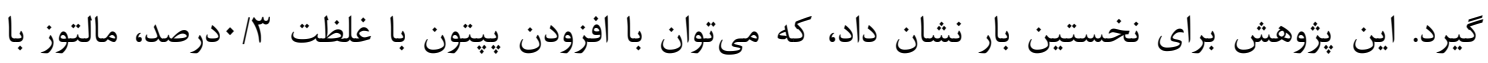

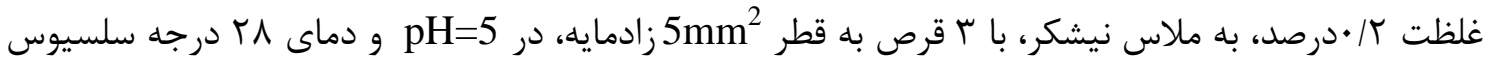

$$
\text { بيشترين زيست توده اين قارج دارويى را توليد كرد. }
$$

وازَّان كليدى: يِيتون، كشت غوطهور، مالتوز، ملاس نيشكر، Ganoderma

$\triangle$ emgoltapeh@gmail.com 


\section{Introduction}

مقدمه

بعضى كونههاى Ganoderma به عنوان توليدكننده طيف وسيعى از محصولات دارويى طبيعى در آسيا و

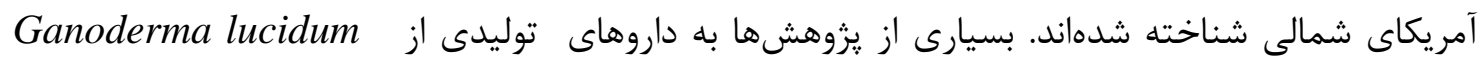
Jong (Curtis) P.Kars نمoh et al. 2007, Cor et al. 2018, et al. 1992 نيمه كرمسيرى و گرمسيرى يافت مىشوند و در شرايط گرم و مرطوب رشد مى كنند (Bilotti et al. 2004).

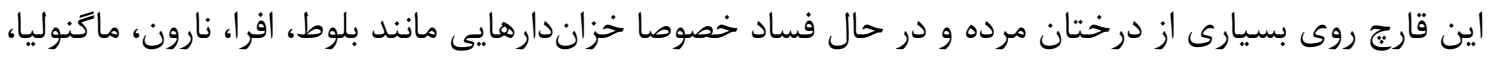

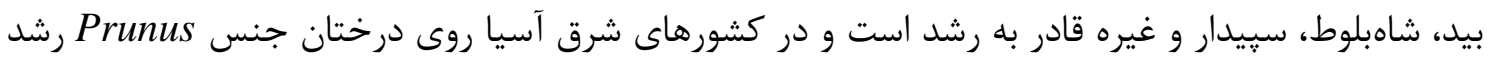

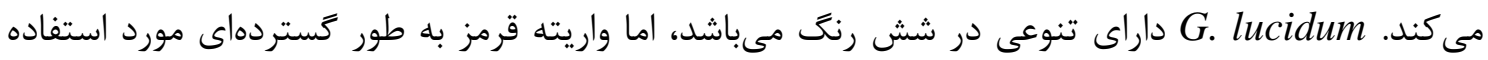

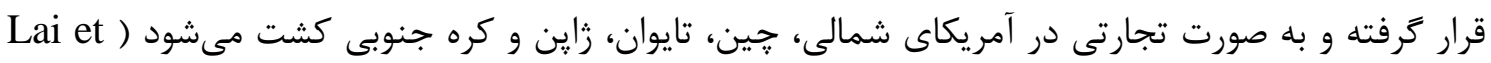

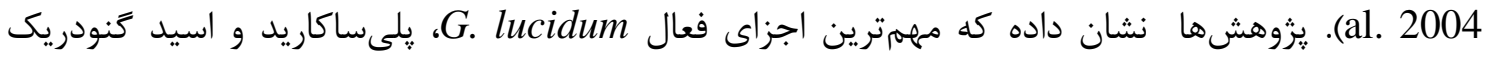

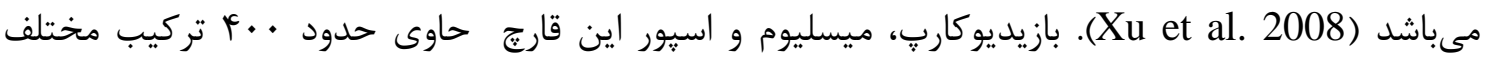

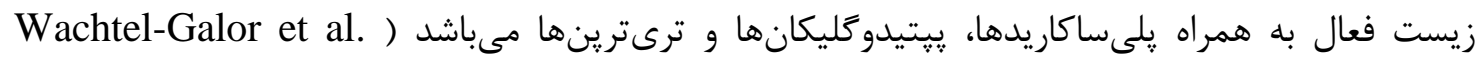

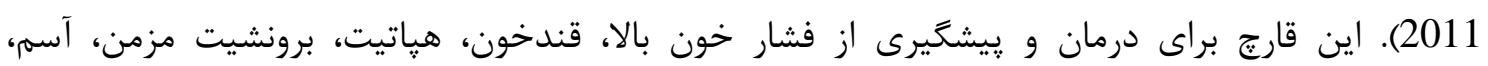

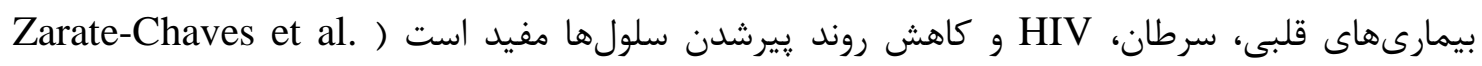

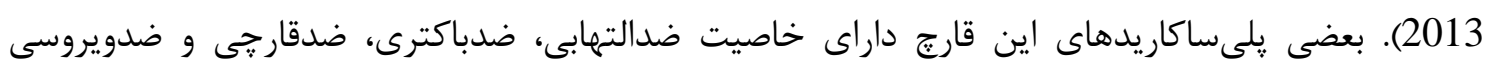

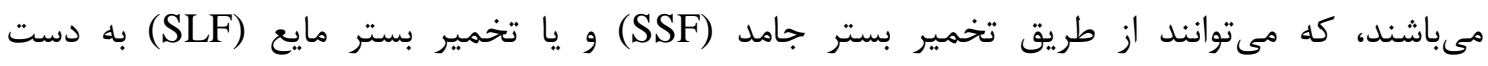

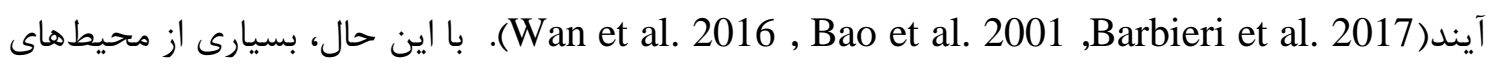

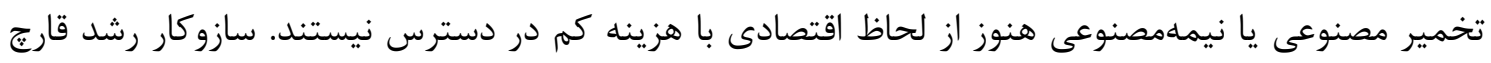

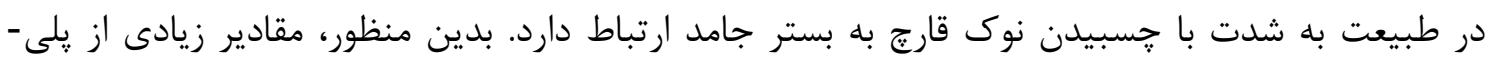

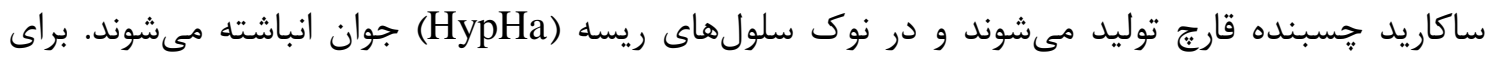

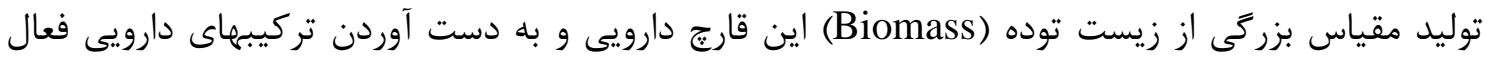

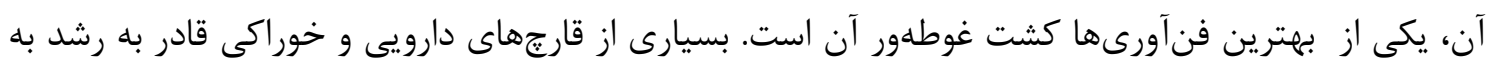

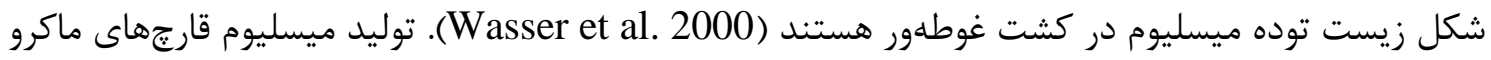

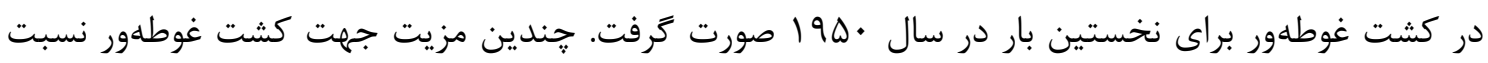

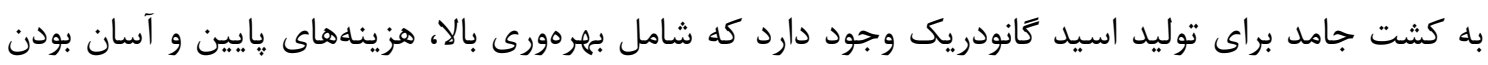

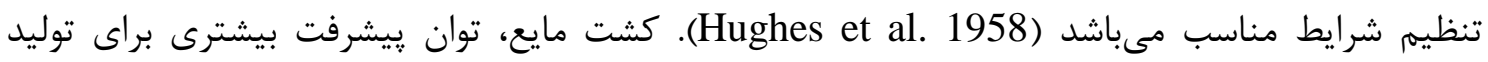

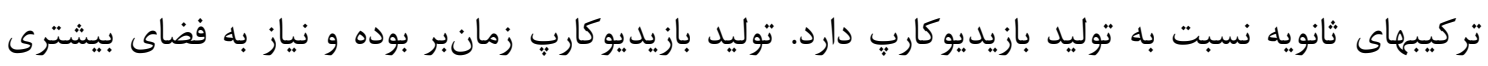

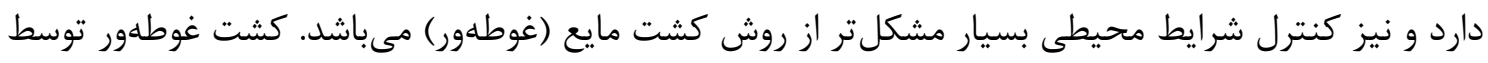
تخمير يك روش جايكزين براى توليد كارآمد تركيبهاى دارويى قارج است (Fang and Zhong 2002).

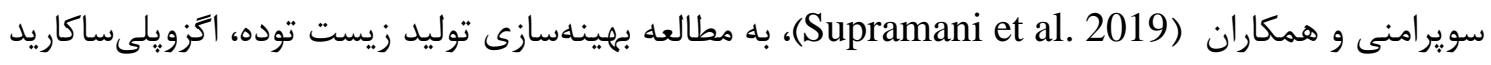

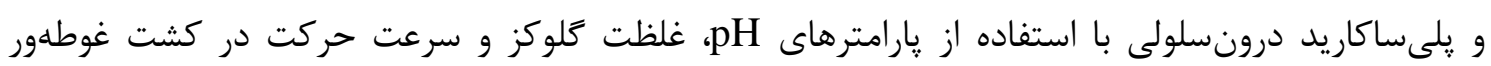
G. يرداختند و ميزان Y lucidum

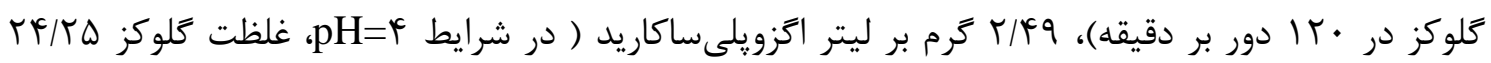




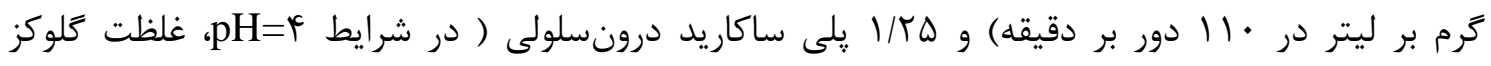

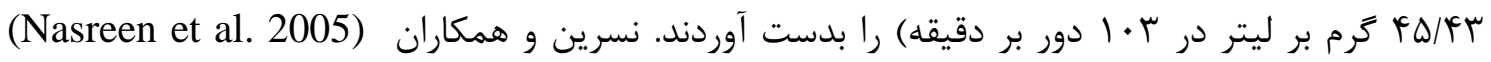

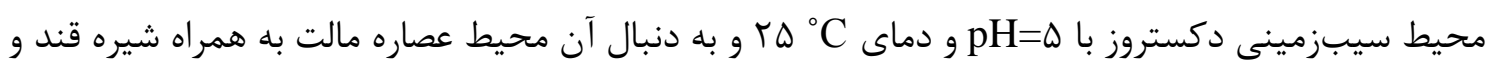

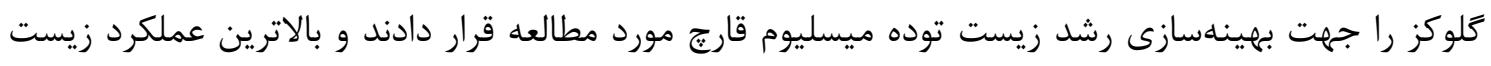

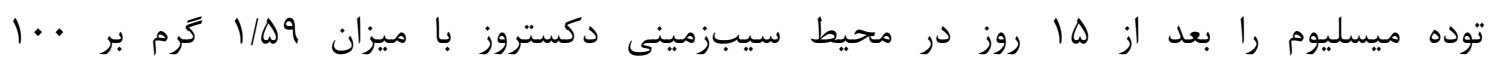

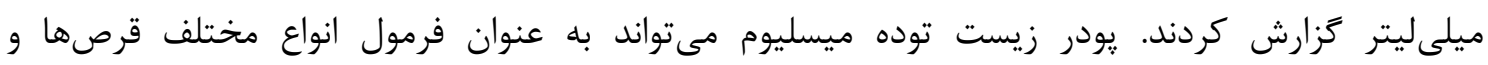

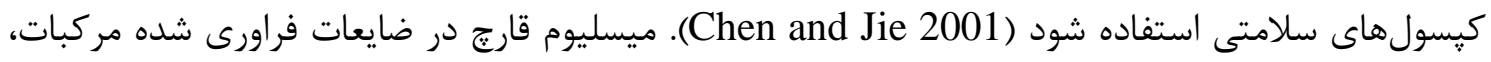
ملاس و ضايعات سولفات و صنايع كاغذ رشد مى كند (Takashaki 1996). محيط كشتى كه ميسليوم در آن آن

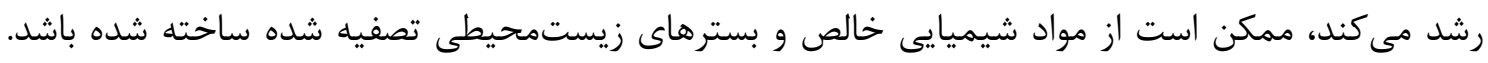

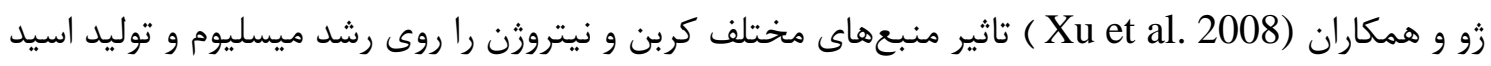

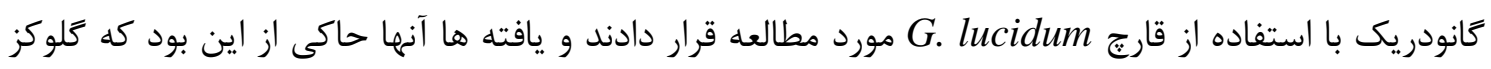

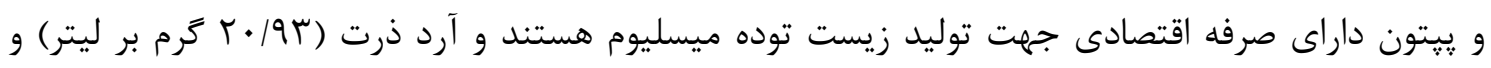

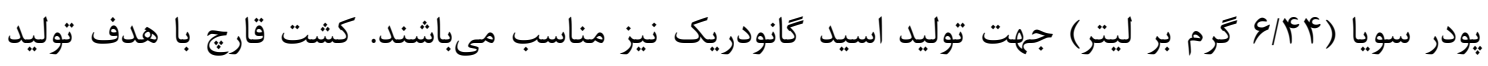

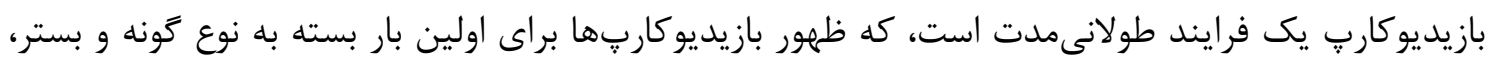

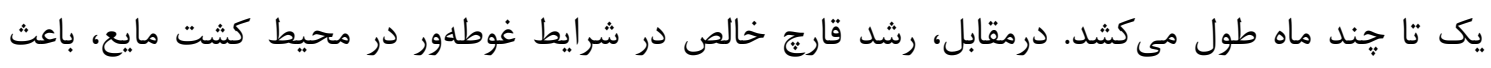

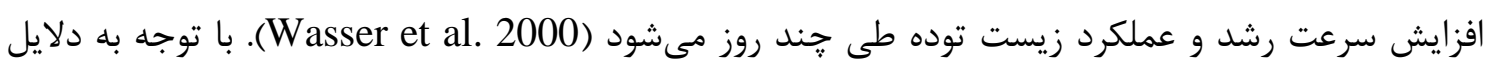

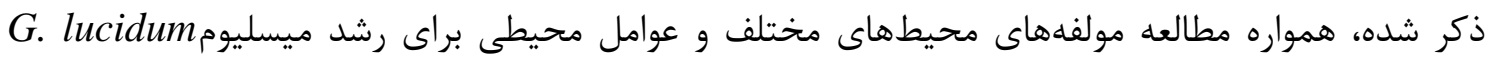

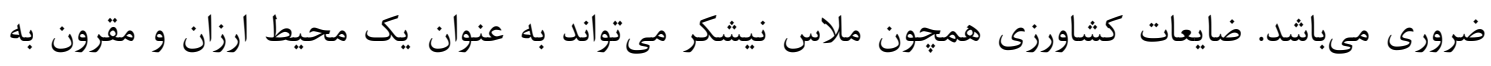

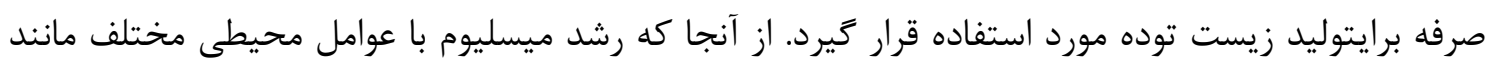

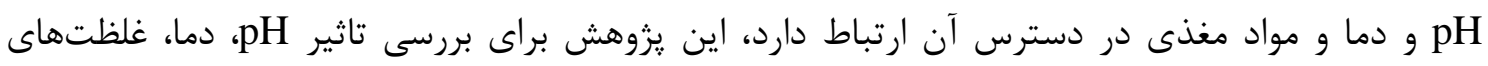

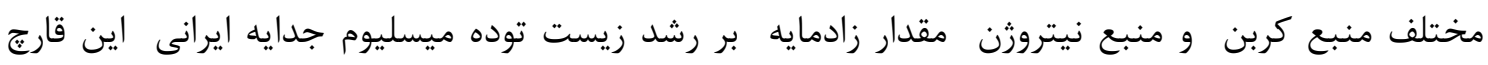

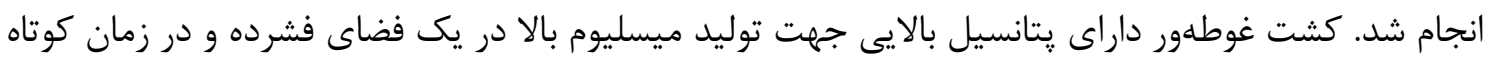

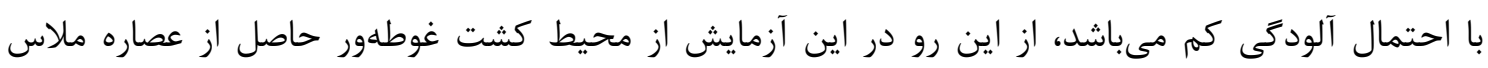

\section{Materials and Methods}

مواد و روشها جدايه قارج و آمادهسازى محيط كشت

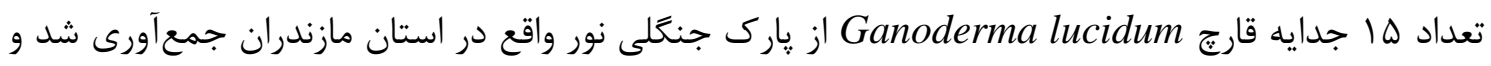

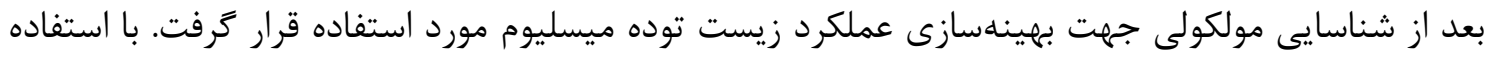

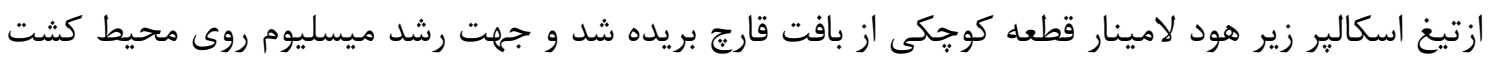

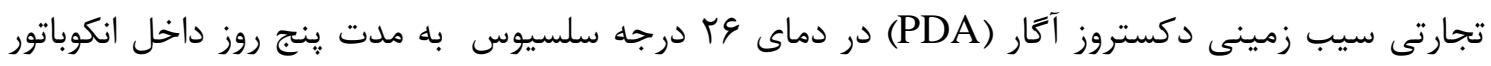

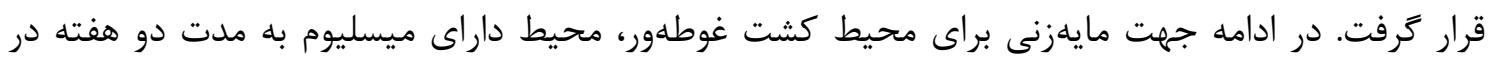

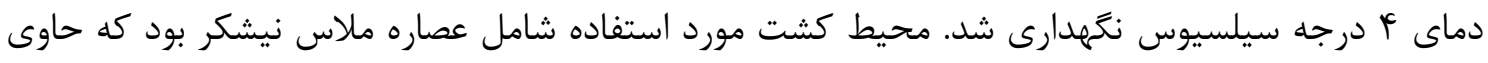

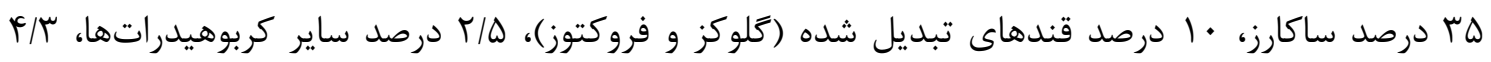




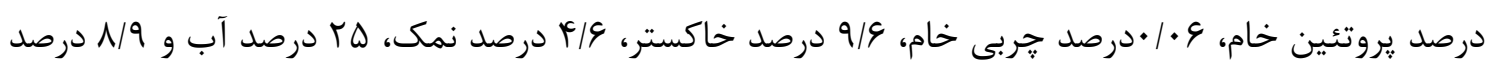

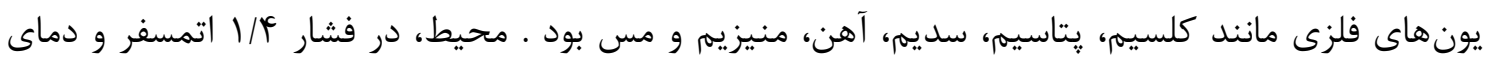

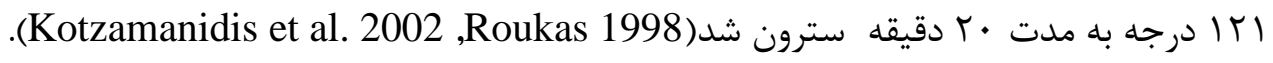

\section{شanoderma lucidum شناسايى ريختى و مولكولى}

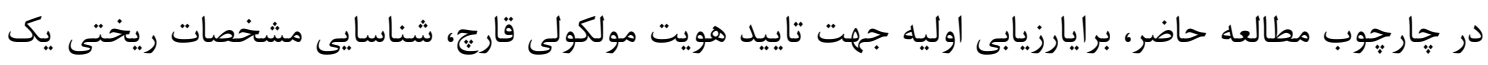

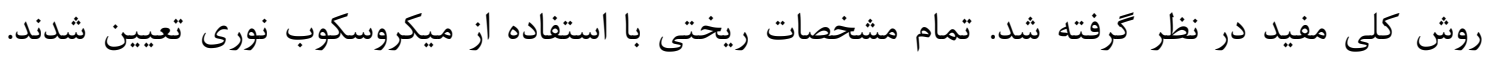

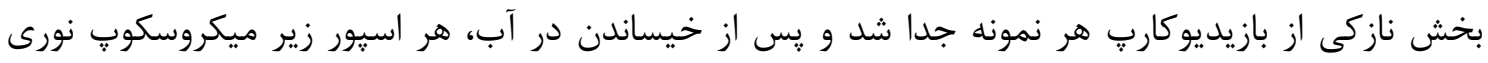

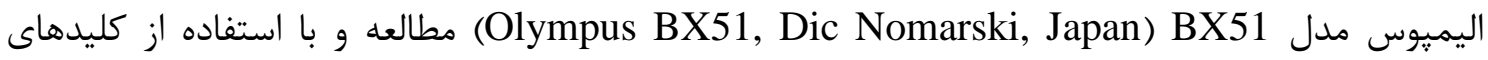
شناسايى معتبر، كونه آن شناسايى شد (Moradali et al. 2007, Steyaert 1972). بآ مشخصات

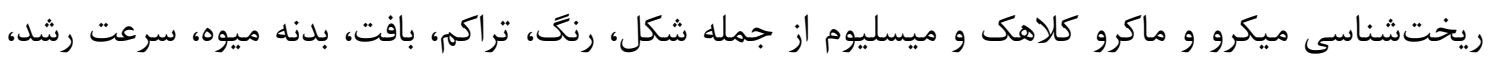

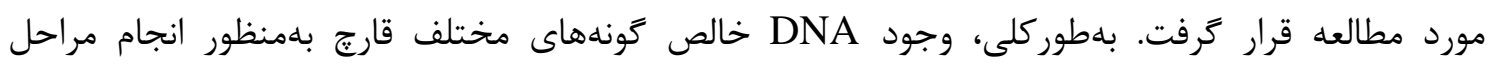
استخراج و كار با PCR ضرورى است. استخراج DNA با استفاده از روش

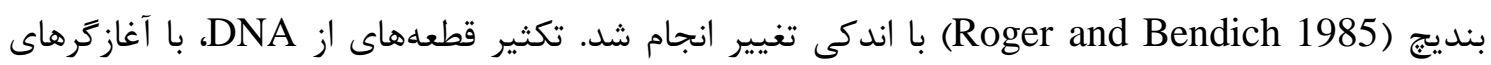

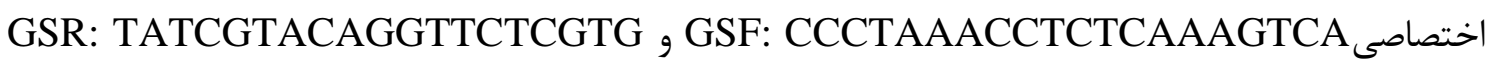

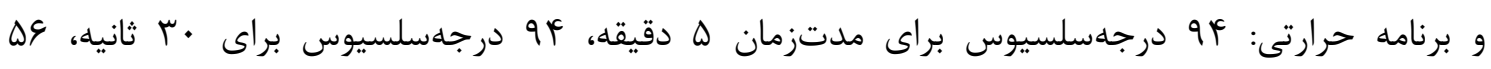

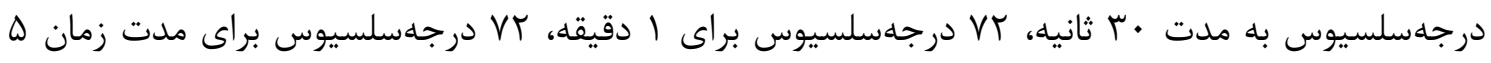

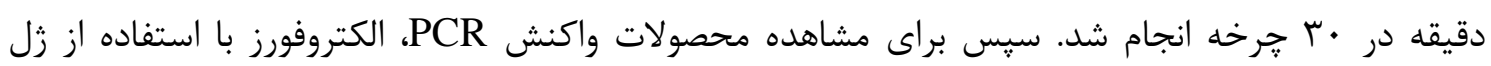
آكًارز يك درصد در انجام شد.

آزمايش اثر متقابل غلظت و نوع منبعهاى نيتروزن بر توليد زيست توده ميسليوم قارج در ملاس نيشكر

براى مطالعه بهينهسازى عملكرد رشد ميسليوم ازمنبعهاى نيتروزن عصاره مخمر، MgsO4.7H2O

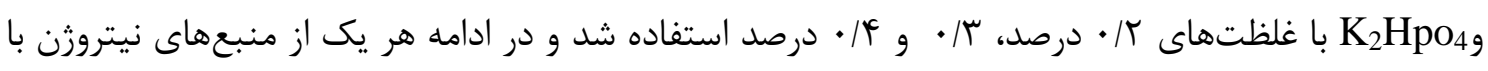

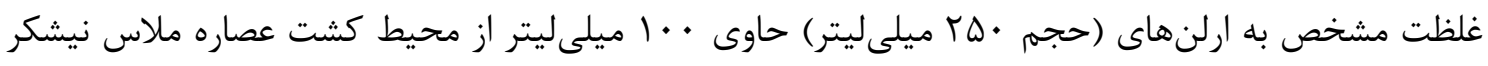

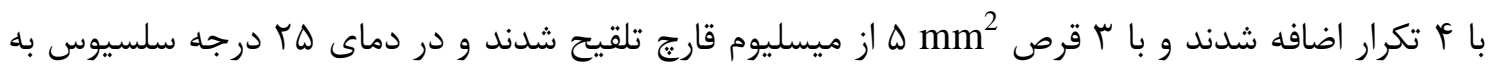

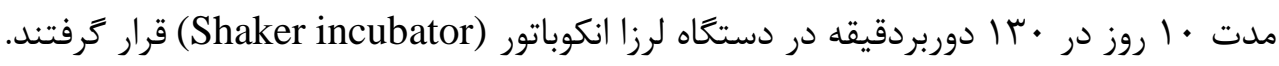
آزمايش اثر متقابل غلظتها و نوع منبعهاى كربن بر توليد زيست توده ميسليوم قارج در ملاس

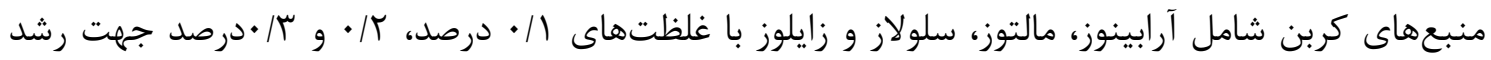

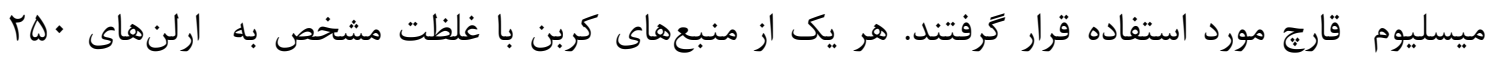

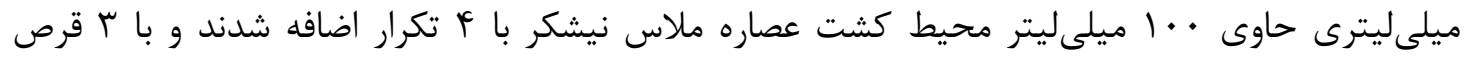

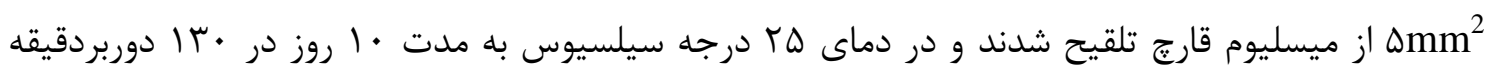
در دستخاه لرزا انكوباتور قرار كرفتند. 


\section{آزمايش اثر pH بر توليد زيست توده ميسليوم قارج در ملاس نيشكر}

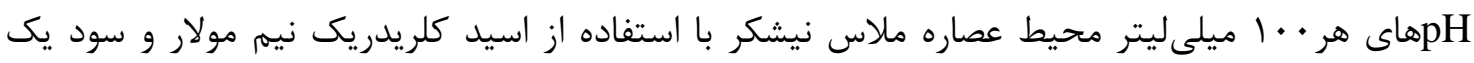

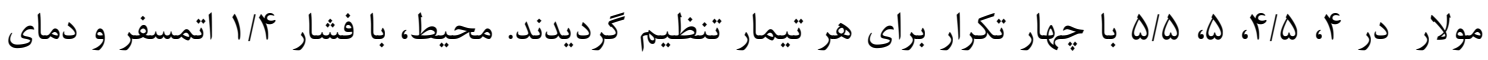

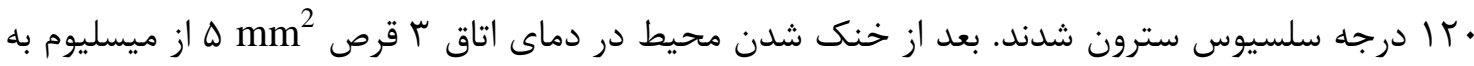

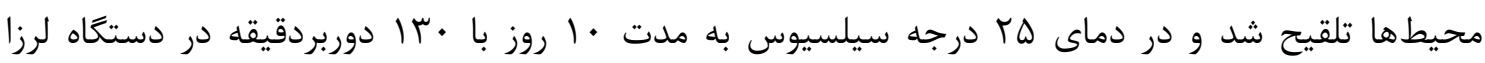
انكوباتور قرار كرفتند.

\section{آزمايش اثر دما بر توليد زيست توده ميسليوم قارج در ملاس نيشكر}

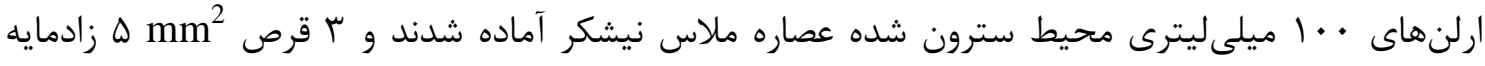

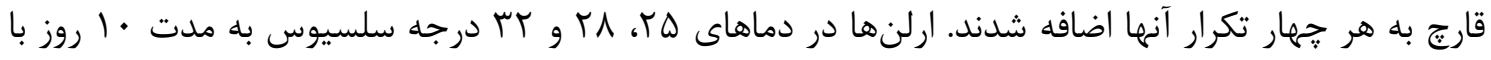

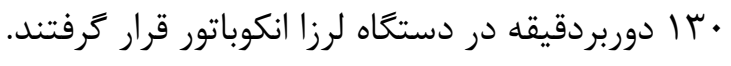

تاثير ميزان زادمايه اوليه قارج بر توليد زيست توده ميسليوم قارج در ملاس نيشكر

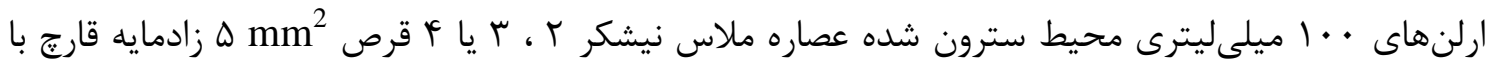

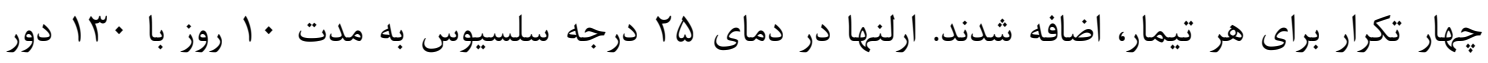
بردقيقه در دستخاه لرزا انكوباتور قرار كرفتند.

\section{برداشت زيست توده ميسليوم قارج در ملاس نيشكر در هر آزمايش}

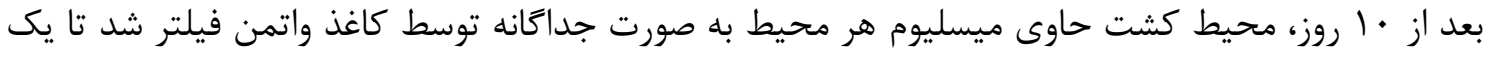

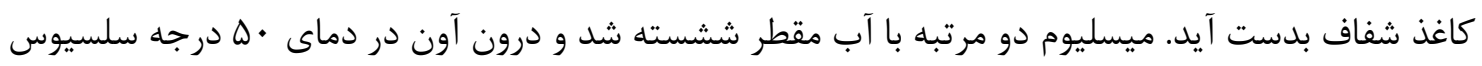

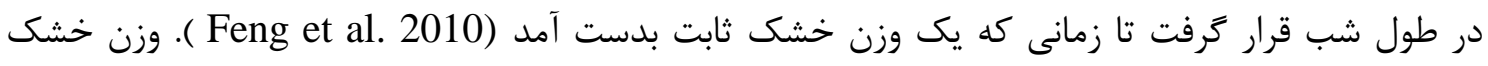

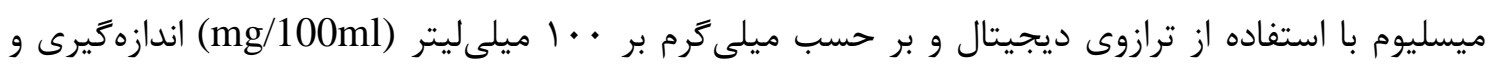

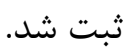

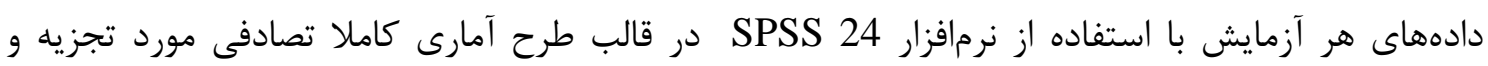
تحليل قرار كرفتند. نرمال بودن دادهها با استفاده از آزمون كولموكروف-اسميرنوف (آزمون

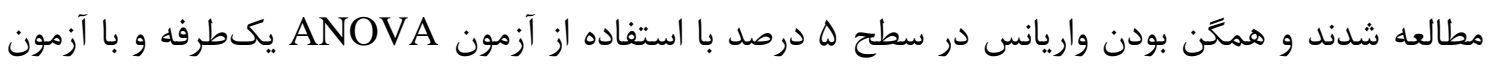
جند دامنهاى دانكن مقايسه شدند.

\section{Results}

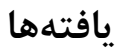

خصوصيات ريختى و مولكولى جدايه قارج Ganoderma lucidum

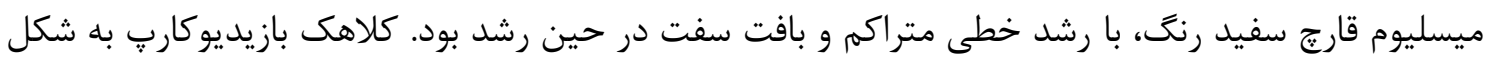

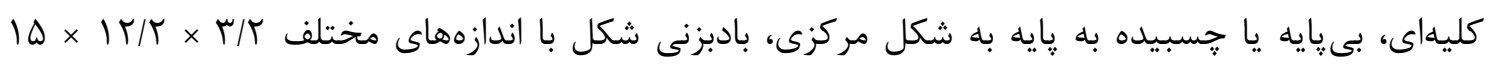

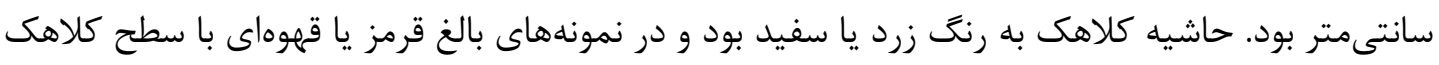



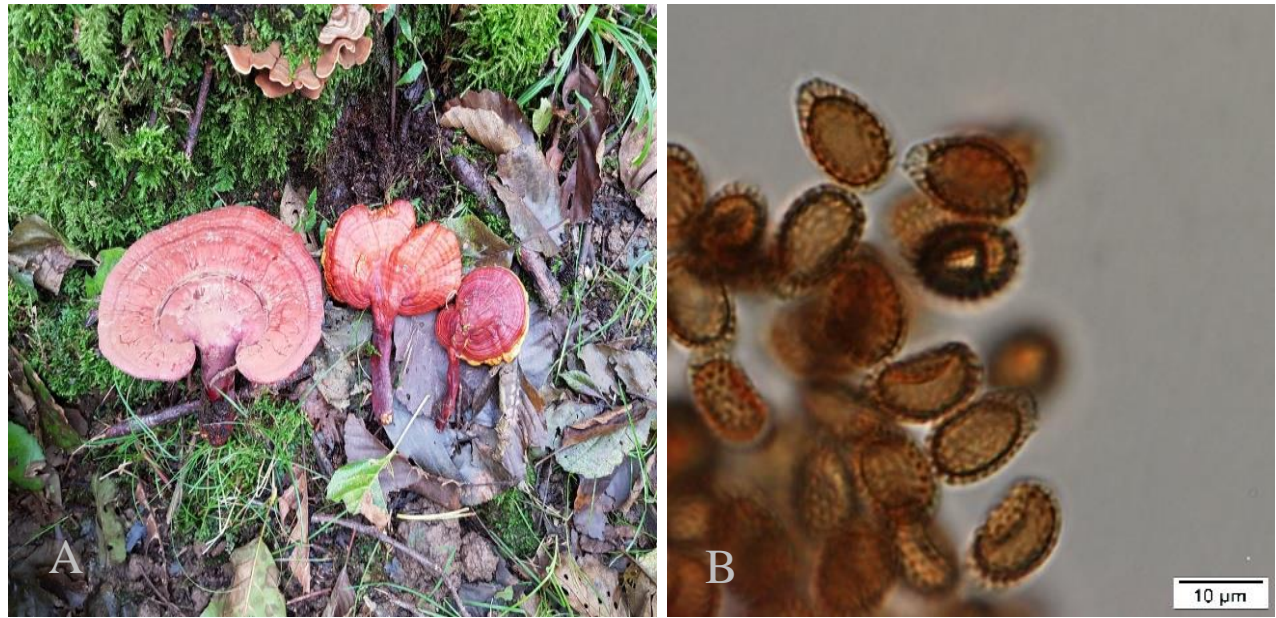

شكل ا. مشخصات ريختى قارج Ganoderma leucidum: A بازيديوكارٍ، B. بازيديوسيورها.

Figure 1. MorpHological characteristics of Ganoderma leucidum: A. Basidiocarp, B. Basidiospores.

براق بود. علاوه بر اين بازيديوسيورها تخمرغى شكل، دوجداره، بيضى شكل و قهوهاى با اندازه

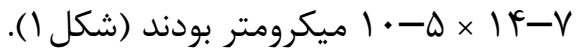

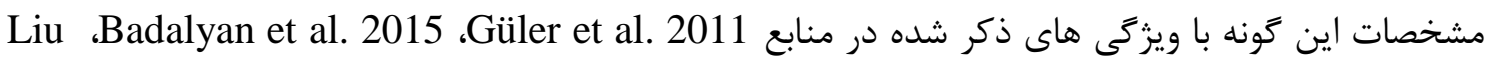
Keypour et al. 2014 ،et al. 2017

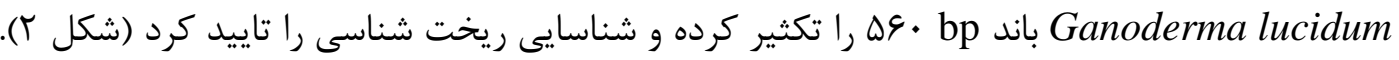

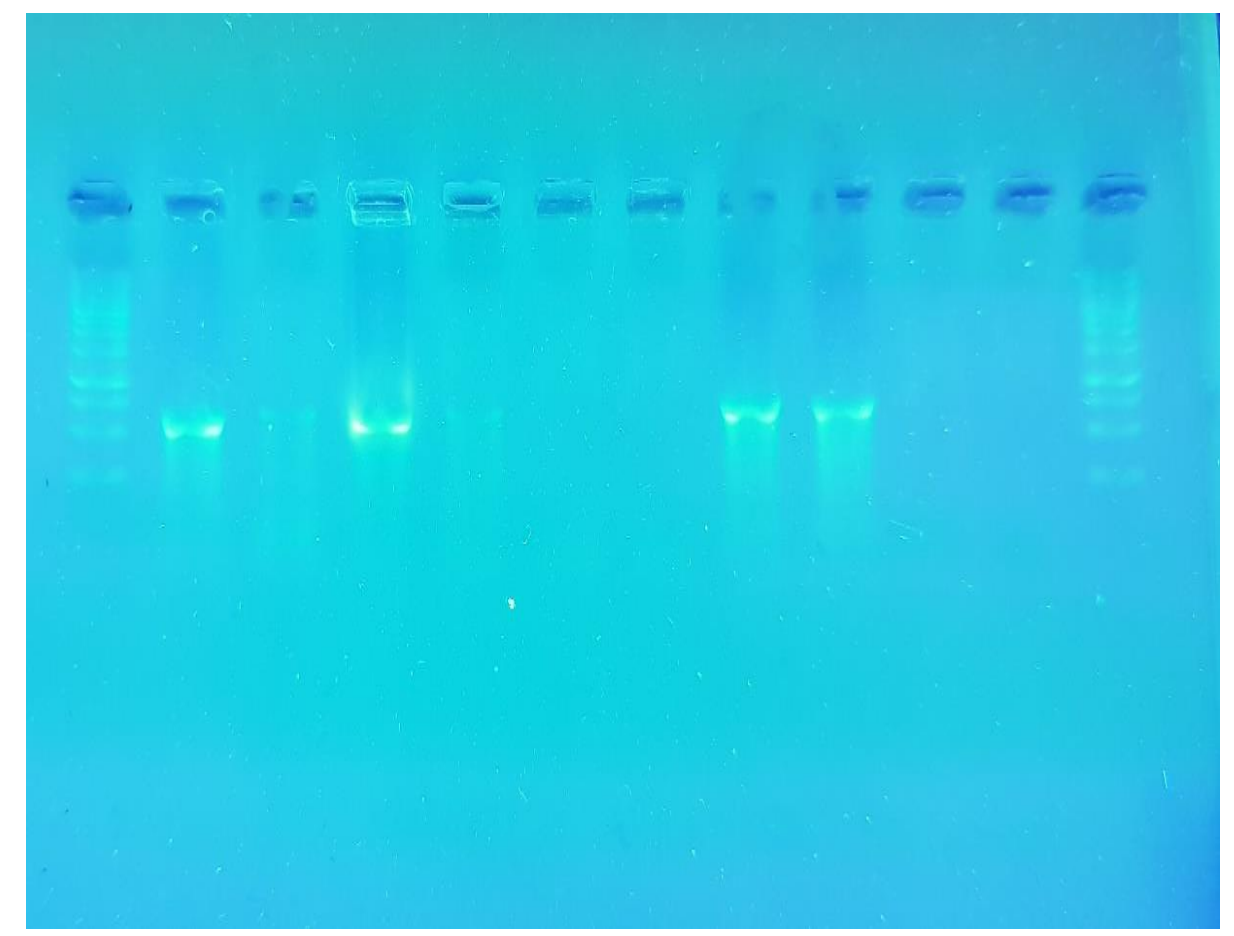

شكل r. شناسايى گونه Ganoderma lucidum با استفاده ازآغازگرهاى اختصاصى GSF و GSR.

Figure 2. Identification of Ganoderma leucidum species using GSF and GSR specific primers. 


\section{اثر متقابل منبع هاى نيتروزن و غلظت آنها بر وزن خشك ميسليوم توليدى قارج در ملاس نيشكر}

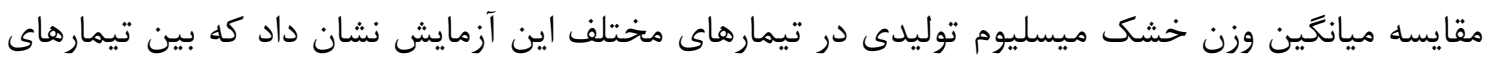

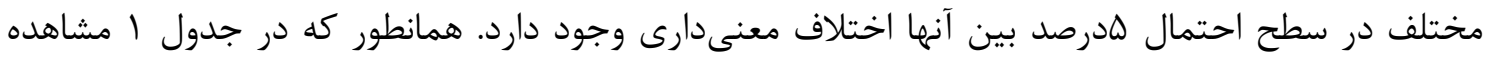

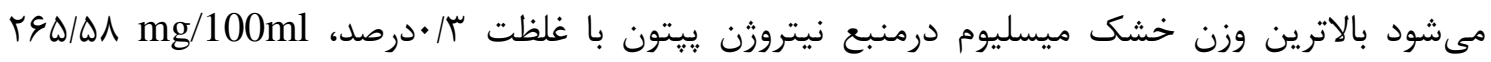

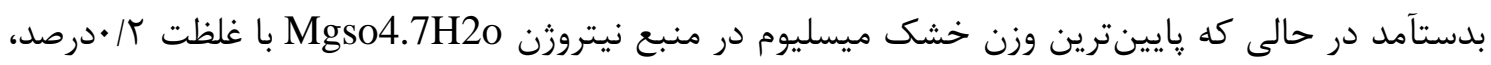

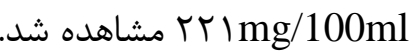

اثر متقابل منبعهاى كربن و غلظت آنها بر وزن خشك ميسليوم توليدى قارج در ملاس نيشكر

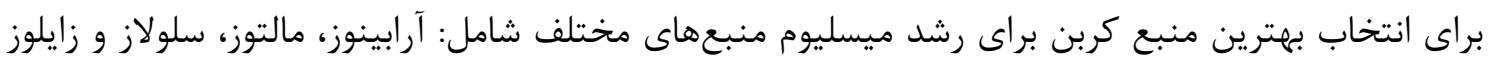

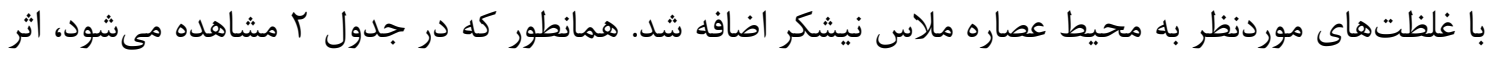

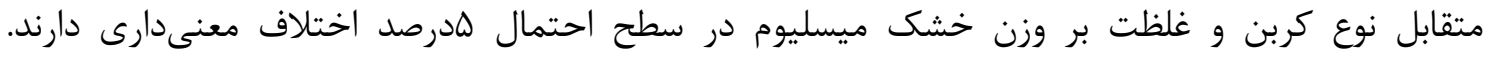

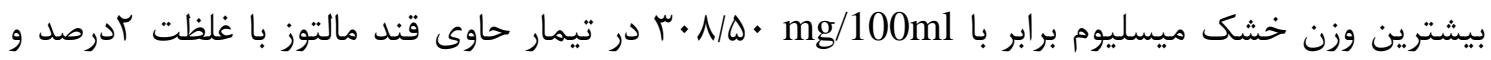

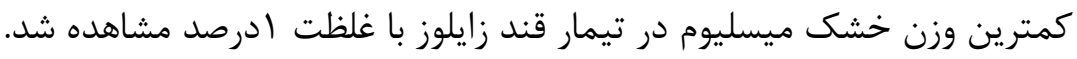

\section{اثر pH و دما بر وزن خشك ميسليوم توليدى قارج در ملاس نيشكر}

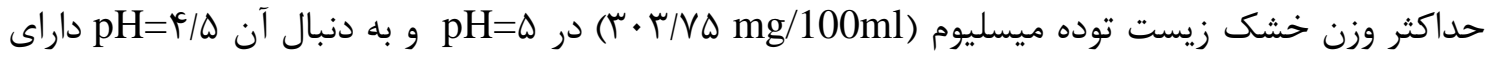
وزن خشك زيست توده

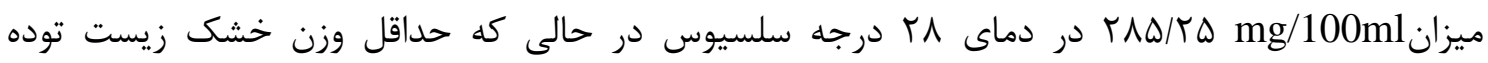

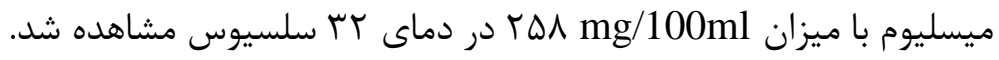

جدول ا. اثر متقابل منبعهاى نيتروزن و غلظتهاى مختلف آنها بر وزن خشك ميسليوم توليدى

.Ganoderma lucidum

Table 1. Interaction of nitrogen sources and their different concentrations on dry weight of mycelium produced by Ganoderma lucidum.

\begin{tabular}{|c|c|c|}
\hline Nitrogen source & $\begin{array}{c}\text { Concentration } \\
(\%)\end{array}$ & $\begin{array}{l}\text { Mycelium dry weight } \\
(\mathrm{mg} / 100 \mathrm{ml})\end{array}$ \\
\hline Peptone & 0.2 & $244.50 \mathrm{dc}$ \\
\hline Yeast extract & 0.3 & $264.50 \mathrm{~b}$ \\
\hline $\mathrm{MgSO}_{4.7} \mathrm{H}_{2} \mathrm{O}$ & 0.4 & $258 \mathrm{~b}$ \\
\hline $\mathrm{K}_{2} \mathrm{Hpo}_{4}$ & 0.2 & $243 \mathrm{dc}$ \\
\hline Peptone & 0.3 & $292.25 \mathrm{a}$ \\
\hline Yeast extract & 0.4 & $264.50 \mathrm{~b}$ \\
\hline $\mathrm{MgSO}_{4.7} \mathrm{H}_{2} \mathrm{O}$ & 0.2 & $221 \mathrm{e}$ \\
\hline $\mathrm{K}_{2} \mathrm{Hpo}_{4}$ & 0.3 & $262 \mathrm{~b}$ \\
\hline Peptone & 0.4 & $264.50 \mathrm{~b}$ \\
\hline Yeast extract & 0.2 & $239.25 \mathrm{~d}$ \\
\hline $\mathrm{MgSO}_{4.7} \mathrm{H}_{2} \mathrm{O}$ & 0.3 & $253 \mathrm{c}$ \\
\hline $\mathrm{K}_{2} \mathrm{Hpo}_{4}$ & 0.4 & $259.75 \mathrm{~b}$ \\
\hline
\end{tabular}


جدول r. اثر متقابل منبعهاى كربن و غلظتهاى آنها بر وزن خشك ميسليوم توليدى

Ganoderma lucidum

Table 2. Interaction of carbon sources and their concentrations on dry weight of mycelium produced by Ganoderma lucidum.

\begin{tabular}{lcc}
\hline Carbon source & $\begin{array}{c}\text { Concentration } \\
(\%)\end{array}$ & $\begin{array}{c}\text { Mycelium dry weight } \\
(\mathrm{mg} / 100 \mathrm{ml})\end{array}$ \\
\hline Arabinose & 1 & $248.50 \mathrm{fe}$ \\
Maltose & 2 & $308.50 \mathrm{a}$ \\
Cellulase & 3 & $275 \mathrm{c}$ \\
Xylose & 1 & $246.25 \mathrm{f}$ \\
Arabinose & 2 & $284.25 \mathrm{~b}$ \\
Maltose & 3 & $287.75 \mathrm{~b}$ \\
Cellulase & 1 & $259.25 \mathrm{~d}$ \\
Xylose & 2 & $260.50 \mathrm{~d}$ \\
Arabinose & 3 & $275.50 \mathrm{c}$ \\
Maltose & 1 & $258 \mathrm{~d}$ \\
Cellulase & 2 & $273 \mathrm{c}$ \\
Xylose & 3 & $256 \mathrm{ed}$ \\
\hline
\end{tabular}

اثر مقدار زاد مايه بر وزن خشك ميسليوم توليدى قارج در ملاس نيشكر

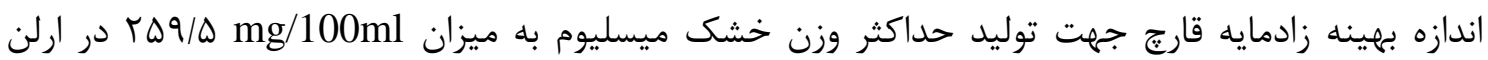

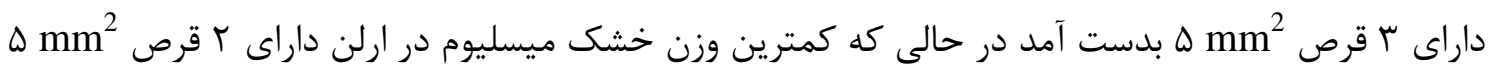

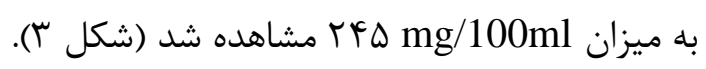

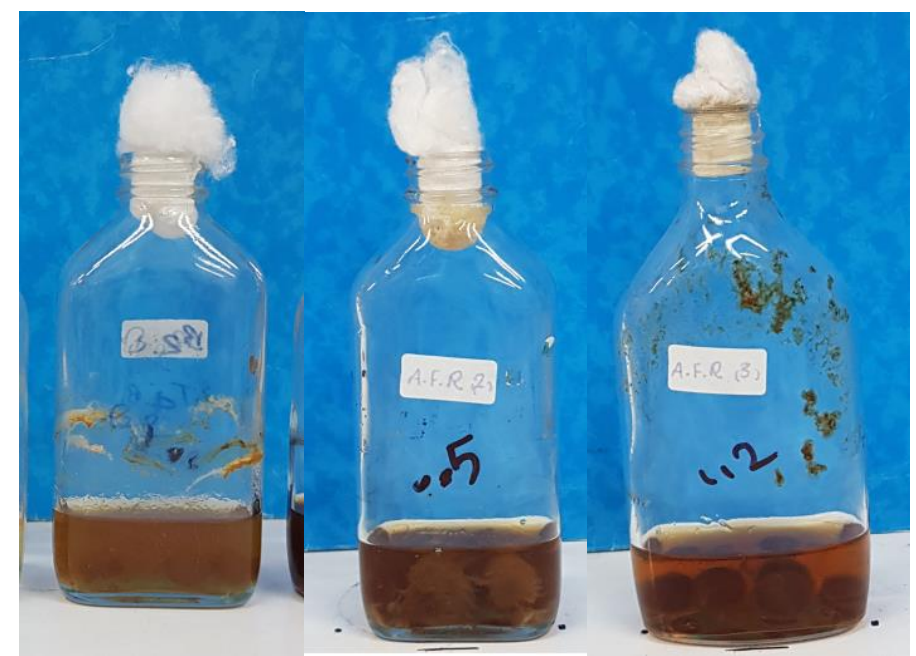

شكل r. توده ميسليومى قارج Ganoderma leucidum در محيط ملاس نيشكر به ترتيب از جٍ به راست

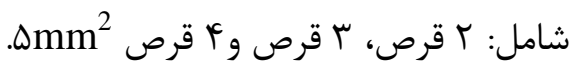

Figure 3. Mycelium mass of Ganoderma leucidum in sugar cane molasses medium from left to right, respectively: 2 pieces, 3 pieces and 4 pieces of $5 \mathrm{~mm}^{2}$. 


\section{Discussion}

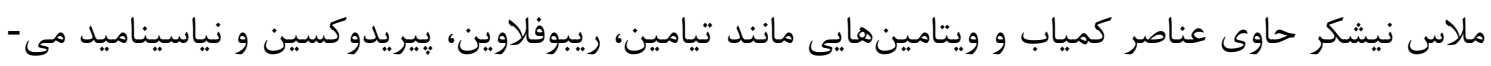

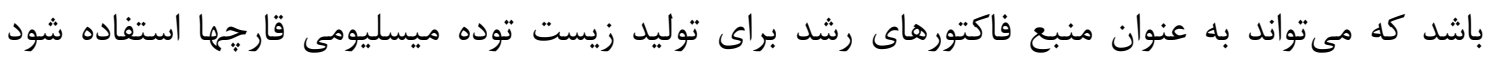

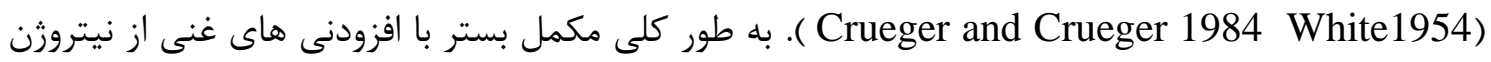
با عث افزايش عملكرد رشد قارج در حين كشت مى شود. از طرف ديخر استفاده از منبعهاى نيتروزن آلى آلى

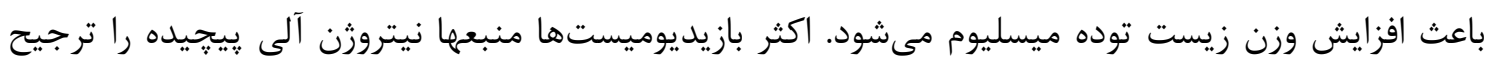

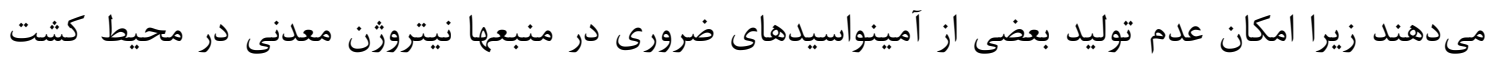

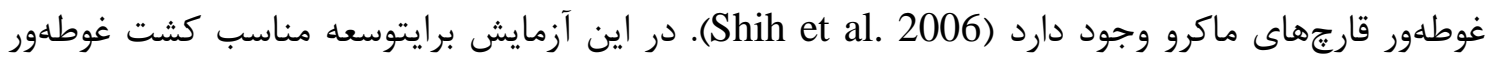

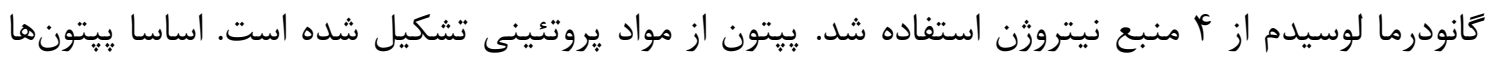

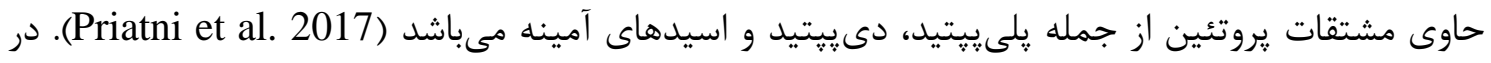

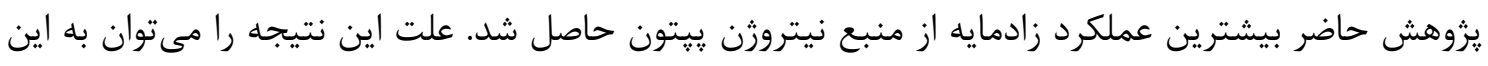

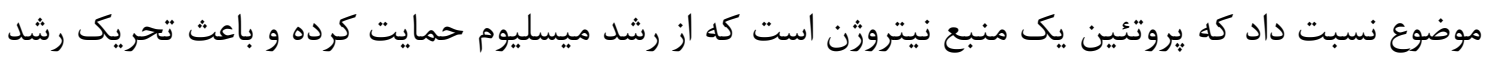

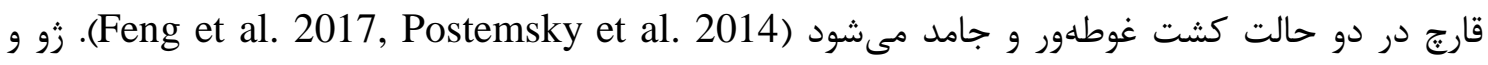

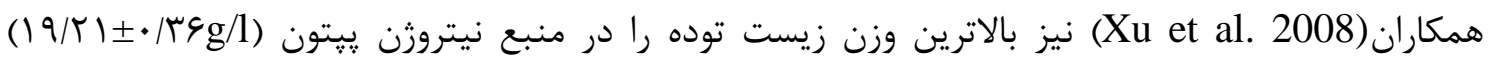
كسب كردند.

اضافه كردن منابع كربن از جمله كليسرول و كلوكز در تقويت زادمايه بسيار موثر مى باشد (Yee 2015). سمبهم

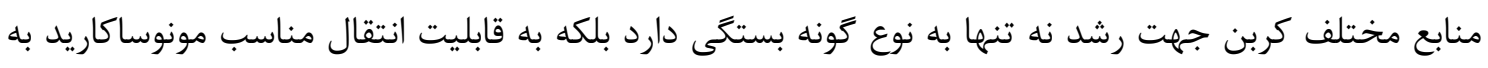

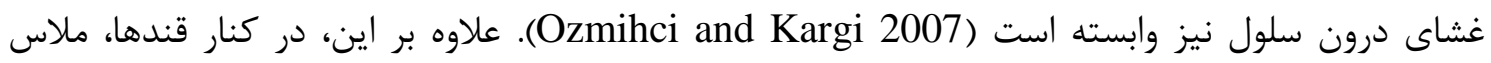

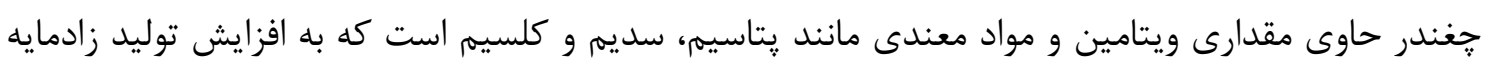

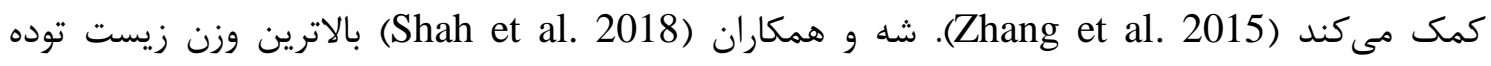

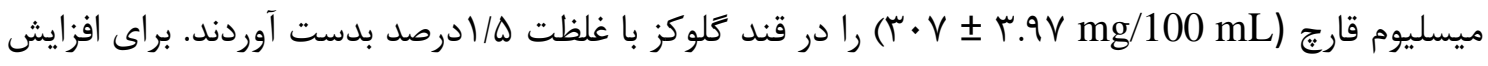

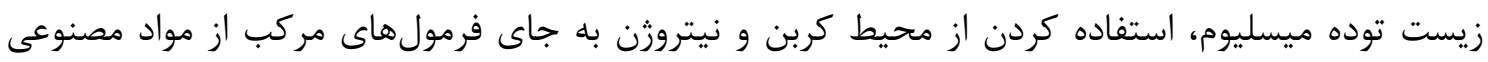

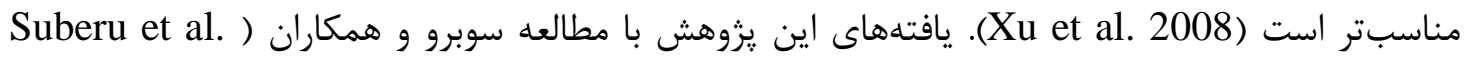

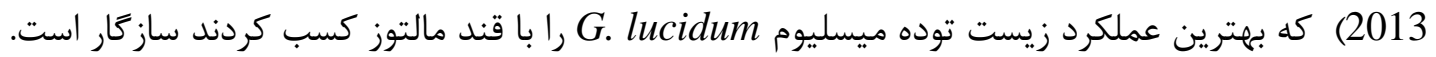

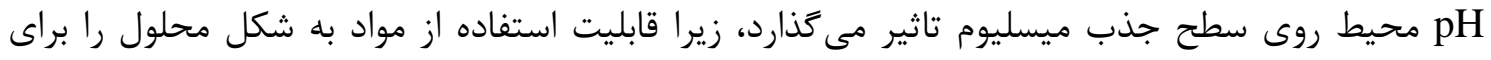

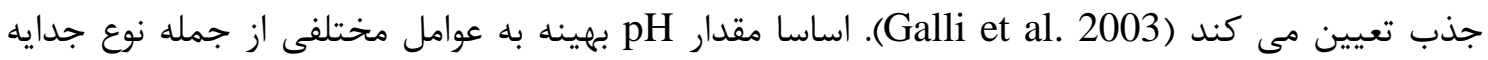

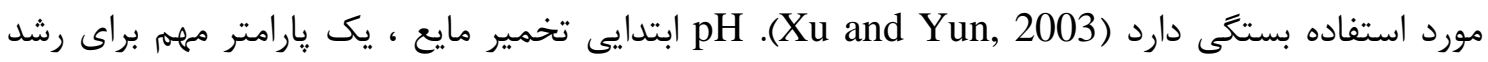

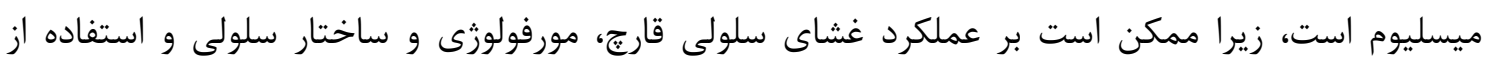

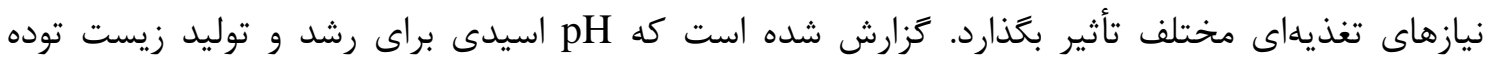

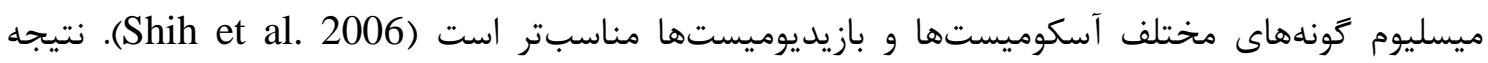

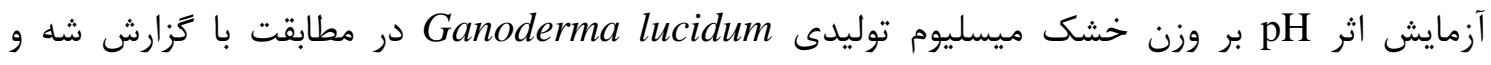

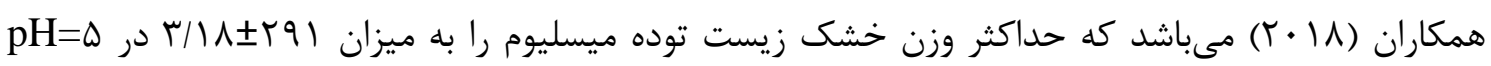
بدست آوردند. 


\section{Conclusion}

كشت غوطهور داراى يتانسيل بالايى براى افزايش توليد ميسليوم قارج دارويى G. lucidum در مدت زمان

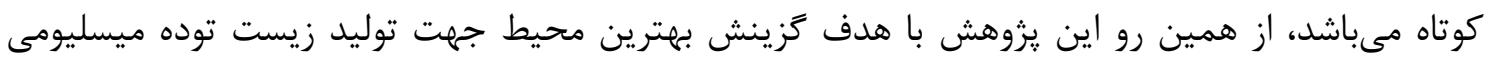

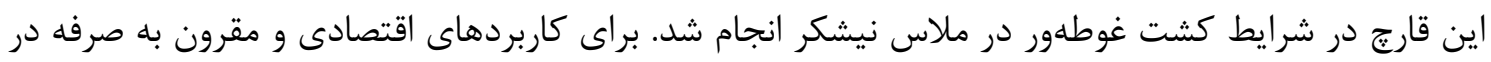

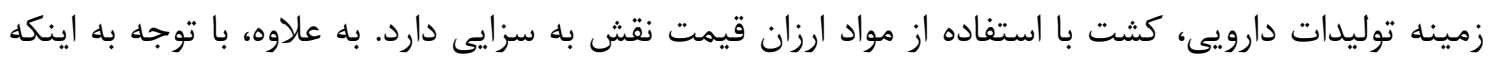

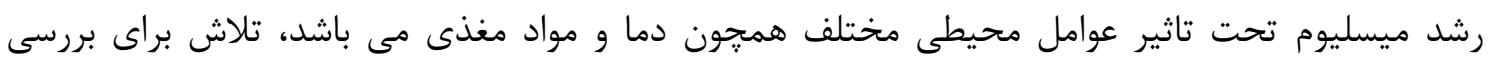

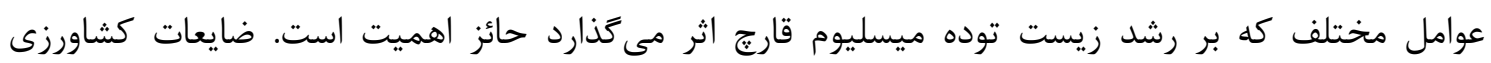

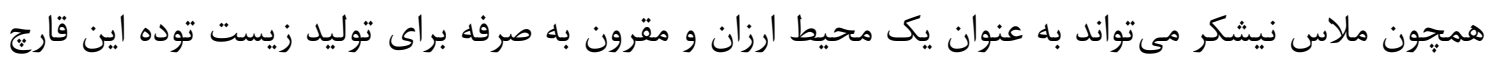

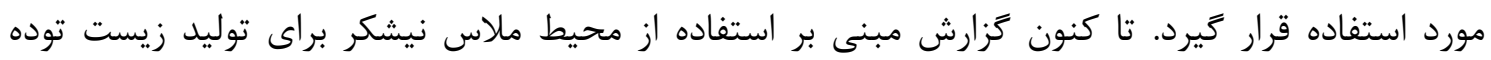

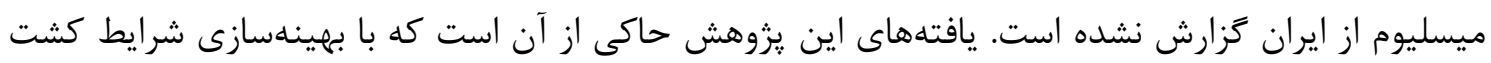

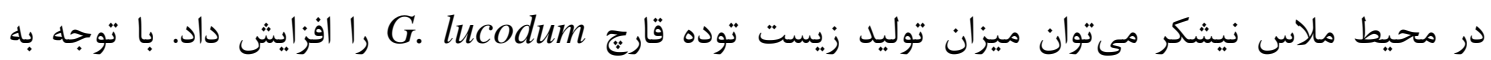

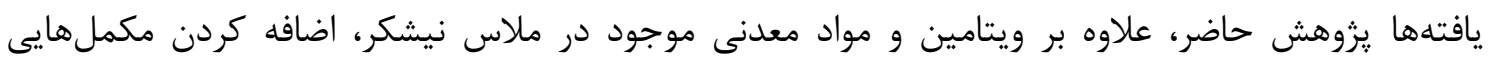

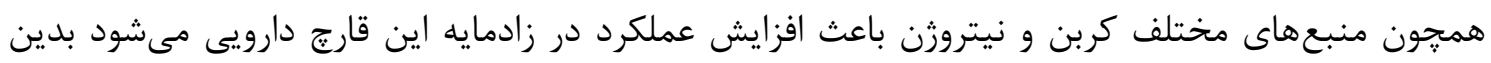

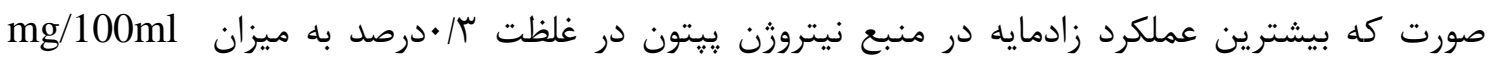

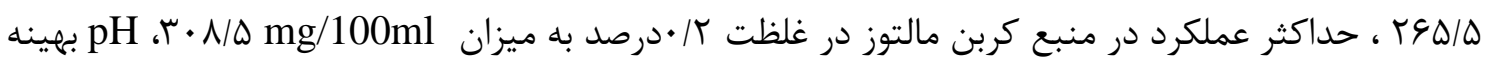

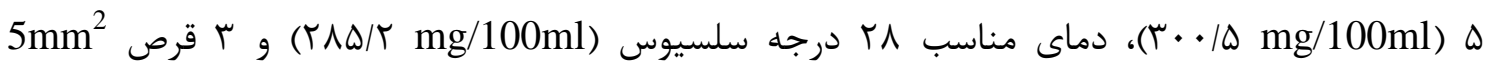

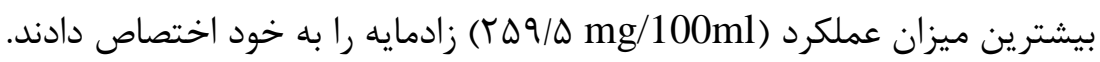

\section{References}

1. Tavana M, Azizi M, Farsi M, Banesh F (2012) Optimization of medium composition for efficient production of mycelial biomass and extracellular polysaccharides in the submerged culture of Ganoderma lucidum. Iranian Journal of Medicinal and Aromatic Plants 28(3): 423-433.

2. Bao X, Fang J, Li X (2001) Structural characterization and immunomodulating activity of a complex glucan from spores of Ganoderma lucidum. Bioscience, Biotechnology and Biochemistry 65(11):2384-2391.

3. Barbieri A, Quagliariello V, Del Vecchio V, Falco M, Luciano A, Amruthraj N, Arra C (2017) Anticancer and anti-inflammatory properties of Ganoderma lucidum extract effects on melanoma and triple-negative breast cancer treatment. Nutrients 9(3):210. https://doi.org/10.3390/nu9030210

4. Boh B, Berovic M, Zhang J, Zhi-Bin L (2007) Ganoderma lucidum and its pHarmaceutically active compounds. Biotechnology Annual Review 13: 265-301.

5. Chen T, Jie Z X (2001) Taurine in the spores and extract powder of log cultivated Ganoderma lucidum. Acta Edulis Fungi 8: 45-46.

6. Cör D, Knez Ž, Knez Hrnčič M (2018) Antitumour, antimicrobial, antioxidant and antiacetylcholinesterase effect of Ganoderma Lucidum terpenoids and polysaccharides: A review. Molecules 23(3):649. 
7. Crueger W, Crueger A (1984) Biotechnology, A Text Book of Industrial Microbiology. Science Tech. Inc., Madison, Wisconsin 180(1):308.

8. Fang Q H, Zhong J J (2002) Effect of initial pH on production of ganoderic acid and polysaccharide by submerged fermentation of Ganoderma lucidum. Process Biochemistry 37(7):769-774.

9. Feng Y L, Li W Q, Wu, X Q, Cheng J W, Ma S Y (2010) Statistical optimization of media for mycelial growth and exo-polysaccharide production by Lentinus edodes and a kinetic model study of two growth morpHologies. Biochemical Engineering Journal 49(1):104-112.

10. Hughes D H, Lynch D L, Somers G F (1958) Mushroom analysis, chromatographic identification of the amino acids and carbohydrates in the cultivated mushroom Aqaricus Campestris L. ex-Fries. Journal of Agricultural and Food Chemistry 6(11):850-853.

11. Jonathan S G, Fasidi I O (2001) Effect of carbon, nitrogen and mineral sources on growth of Psathyerella atroumbonata (Pegler), a Nigerian edible mushroom. Food Chemistry 72(4): 479-483.

12. Jong S C, Birmingham J M (1992) Medicinal benefits of the mushroom Ganoderma lucidum. Advances in Applied Microbiology. 37: 101-134.

13. Kotzamanidis C H, Roukas T, Skaracis G (2002) Optimization of lactic acid production from beet molasses by Lactobacillus delbrueckii NCIMB 8130. World Journal of Microbiology and Biotechnology 18(5): 441-448.

14. Lai T, Gao Y, Zhou S (2004) Global marketing of medicinal Ling Zhi mushroom Ganoderma lucidum (W. Curt.: Fr.) Lloyd (Aphyllophoromycetideae) products and safety concerns. International Journal of Medicinal Mushrooms 6(2)189-194.

15. Lee B C, Bae J T, Pyo H B, Choe T B, Kim S W, Hwang H J, Yun J W (2004) Submerged culture conditions for the production of mycelial biomass and exopolysaccharides by the edible Basidiomycete Grifola frondosa. Enzyme and Microbial Technology 35(5):369-376.

16. Nasreen Z, Kausar T, Nadeem M, Bajwa R (2005) Study of different growth parameters in Ganoderma lucidum. Micología Aplicada International 17(1): 5-8.

17. Pilotti C A, Sanderson F R, Aitken E A, Armstrong W (2004) MorpHological variation and host range of two Ganoderma species from Papua New Guinea. Mycopathologia 158(2): 251-265.

18. Roukas T (1998) Pretreatment of beet molasses to increase pullulan production. Process Biochemistry 33(8): 805-810.

19. Shah Pooja, Modi A (2018) Optimization of Culture Conditions for Biomass Production of Ganoderma lucidum. International Journal of Current Microbiology (7)2:1882-1889.

20. Shih L, Pan K, Hsieh C (2006) Influence of nutritional components and oxygen supply on the mycelial growth and bioactive metabolites production in submerged culture of Antrodia cinnamomea. Process Biochemistry 41(5):1129-1135. 
21. Suberu H A, Lateef A A, Bello I M, Daudu O A Y (2013) Mycelia biomass yield of Ganoderma lucidum mushroom by submerged culture. Nigerian Journal of Technological Research 8(2):64-67.

22. Supramani S, Ahmad R, Ilham Z, Annuar M S M, Klaus A, Wan-Mohtar W A A Q (2019) Optimisation of biomass, exopolysaccharide and intracellular polysaccharide production from the mycelium of an identified Ganoderma lucidum strain QRS 5120 using response surface methodology. AIMS Microbiology 5(1):1938 .

23. Takashaki M (1996) Studies on bioactive substances and medical effect of Reishi (Ganoderma lucidum). Foods and Food Ingredients Journal of Japan 167:6985 .

24. Wachtel-Galor S, Yuen J, Buswell J A, Benzie I F (2011) Ganoderma lucidum (Lingzhi or Reishi). In Herbal Medicine Biomolecular and Clinical Aspects. 2nd edition. CRC Press/Taylor and Francis.

25. Wan W A A Q I, Latif N A, Harvey L M, McNeil B (2016) Production of exopolysaccharide by Ganoderma lucidum in a repeated-batch fermentation. Biocatalysis and Agricultural Biotechnology 6:91-101.

26. Wasser S P, Sokolov D, Reshetnikov S V, Timor-Tismenetsky M (2000) Dietary supplements from medicinal mushrooms: diversity of types and variety of regulations. International Journal of Medicinal Mushrooms. 2(1):1-19.

27. White J (1954) Yeast Technology. Chapman and Hall, Ltd., London.

28. Xu P, Ding Z Y, Qian Z, Zhao C X, Zhang K C (2008) Improved production of mycelial biomass and ganoderic acid by submerged culture of Ganoderma lucidum SB97 using complex media. Enzyme and Microbial Technology 42(4):325-331.

29. Zárate-Chaves C A, Romero-Rodríguez M C, Niño-Arias F C, Robles-Camargo J, Linares-Linares M, Rodríguez-Bocanegra M X, Gutiérrez-Rojas I (2013) optimizing a culture medium for biomass and phenolic compounds production using Ganoderma lucidum. Brazilian Journal of Microbiology 44(1):215-223.

30. Moradali MF, Hedjaroude G-A, Mostafavi H, Abbasi M, Ghods S, Sharifi Tehrani A (2007) The genus Ganoderma (Basidiomycota) in Iran. Mycotaxon 99:251-69.

31. Steyaert RL (1972) Species of Ganoderma and related genera mainly of the Bogor and Lieden herbaria. Persoonia 7:55-118.

32. Rogers S O, Bendich A J (1985) Extraction of DNA from milligram amounts of fresh, herbarium and mummified plant tissues. Plant Molecular Biology 5(2):69-76.

33. Liu S R, Ke B R, Zhang W R, Liu X R, Wu X P (2017) Breeding of new Ganoderma lucidum strains simultaneously rich in polysaccharides and triterpenes by mating basidiospore-derived monokaryons of two commercial cultivars. Scientia Horticulturae 216:58-65. 
34. Güler P, Kutluer F, Kunduz İ (2011) Screening to Mycelium Specifications of Ganoderma lucidum (Fr.) Karst (Reishi). Hacettepe Journal of Biology and Chemistry 39(4): 397-401.

35. Badalyan S M, Shnyreva A V, Lotti M, Zambonelli A (2015) Genetic resources and mycelial characteristics of several medicinal polypore mushrooms (Polyporales, Basidiomycetes). International Journal of Medicinal Mushrooms 17(4):371-384.

36. Galli E F D M, Di Mario F, Rapana P, Lorenzoni P, Angelini R (2003) Copper biosorption by Auricularia polytricha. Letters in Applied Microbiology. 37(2):133137.

37. Xu, C P, Yun J W (2003) Optimization of submerged- culture conditions for mycelial growth and exo- biopolymer production by Auricularia polytricha (wood ears fungus) using the methods of uniform design and regression analysis. Biotechnology and Applied Biochemistry 38(2):193-199.

38. Feng J, Zhang J S, Feng N, Yan M Q, Yang Y, Jia W, Lin C C (2017) A novel Ganoderma lucidum G0119 fermentation strategy for enhanced triterpenes production by statistical process optimization and addition of oleic acid. Engineering in Life Sciences 17(4): 430-439.

39. Postemsky P D, Delmastro S E, Curvetto N R (2014) Effect of edible oils and $\mathrm{Cu}$ (II) on the biodegradation of rice by-products by Ganoderma lucidum mushroom. International Biodeterioration and Biodegradation 93:25-32.

40. Priatni S, Kosasih W, Budiwati T A, Ratnaningrum D (2017) Production of peptone from boso fish (Oxyeleotris marmorata) for bacterial growth medium. In IOP Conference Series: Earth and Environmental Science 60(1):12009.

41. Yee W (2015) Feasibility of various carbon sources and plant materials in enhancing the growth and biomass productivity of the freshwater microalgae Monoraphidium griffithii NS16. Bioresource Technology 196:1-8.

42. Ozmihci S, Kargi F (2007) Kinetics of batch ethanol fermentation of cheesewhey powder (CWP) solution as function of substrate and yeast concentrations. Bioresource Technology 98(16): 2978-2984.

43. Zhang Y Y, Bu Y F, Liu J Z (2015) Production of L-ornithine from sucrose and molasses by recombinant Corynebacterium glutamicum. Folia Microbiologica 60(5): 393-398. 